being impossible in the present case, since the By-laws had not been in force, the Assembly appointed the present Committee of Officers to serve until the next General Assembly.

The Royal Institute of Navigation had proposed that IAIN should sponsor an annotated bibliography of methods and tables for astronomical navigation and a description of the project had been circulated to all Member Institutes with a letter requesting their concurrence with the procedure proposed. This included the appointment of a small Project Committee to work closely with the Director, Capt. (Dr.) C. H. Cotter; inviting the support of international organizations such as UNESCO, IHB, IAU, and securing the cooperation of national organizations and individuals within different countries. The Secretary General reported that the Member Institutes had all agreed to support the project and to the composition of the Project Committee (H. C. Freiesleben, P. Hugon, A. B. Moody and D. H. Sadler).

IAIN is now responsible amongst other things for the organization of the international congresses which the Institutes between them have sponsored every three years or so over the last twenty years. The Assembly agreed that, subject to formal agreement by the Council of the Royal Institute of Navigation, the next congress would be held in the United Kingdom in 1979, probably in the Autumn.

A paper submitted by the Radio Navigation Committee of the United States Institute suggested that the Institutes between them, through the medium of IAIN, could perform a very useful function by exchanging views and, if a concensus can be established, making known to the appropriate authorities the requirements of the navigational community in terms of radio transmission. The Assembly agreed to take on this task and, in view of the coming meeting of the International Telecommunications Union, suggested that coordination be effected within the next eighteen months in those areas which might involve matters of interest to the ITU.

During the Assembly the Nautical Society of Japan, which had hitherto been concerned almost exclusively with marine navigation, announced the change of its title to The Japanese Institute of Navigation.

\title{
R. B. Michell
}

Ir is with regret that we record the death, on 23 June 1976 , of Lieut.-Cmdr. R. B. Michell, O.B.E., D.S.C.,.R.N.(ret.), a founder Member and Fellow of this Institute.

When the Institute came into being, on I 2 March 1947, it was the spokesmen for the two services and the Ministries concerned with navigation who put the proposal that 'an Institute of Navigation be formed' to the inaugural meeting in the Council Chamber of Lloyd's Register of Shipping. But before that a great deal of spade work had been put in by a number of less exalted persons, sustained only by their enthusiasm, the members of the Steering Committee. Not the least conspicuous among these founding fathers was Dick Michell, a Lieutenant in the Royal Navy with a distinguished record in navigation during the war and then on loan to the Ministry of Transport. He had taken part in the second 
International Meeting on Radio Aids to Marine Navigation, and was shortly afterwards to command H.M.S. Redpole, the training vessel for H.M. School of Navigation, H.M.S. Dryad.

Michell was one of a brilliant generation of Service navigators whose practice of the art had been forged under the stern demands of war and whose enthusiasm for it long outlasted the battle. One is reminded of people like P. G. Satow, an exact contemporary, and, in the air, of perhaps the most gifted of them all, E. W. Anderson. The Institute would not have been formed without them for it was the navigators who felt the need to continue in peacetime the fruitful collaboration that had existed during the war between all sections of the navigational community-astronomers, engineers, oceanographers and so on no less than navigators. And it was fortunate for the character of the new body that it was this way round, for, however abstruse or theoretical may appear some of its more specialized proceedings, the character of the Institute has remained indelibly operational.

Dick was in Navigation all his life and it is I think as a navigator that he would like to be remembered. When he left the Navy he joined Decca Radar Ltd. where he ended up as Manager of the Naval Sales Division, in which capacity in 1974 he was awarded the O.B.E. One would imagine that much of his value to the Company, and indeed to its clients, was precisely his ability to see things from the navigator's point of view. He was not a ready communicator but he had a fertile mind and always enough enthusiasm and perseverance to get his ideas through. Most of his professional interest was in the field of radar and radio aids but in 1953 he devised an ingenious method, later to be adopted by the Admiralty, of using a star lattice to provide a rapid interpretation of astronomical position lines and to relate the observations continuously to the ship's dead reckoning position.

I owe Dick Michell a personal debt of gratitude, for it was he who interviewed me on behalf of the Steering Committee when I applied for the post of Executive Secretary, and one must assume reported favourably.

M.W.R. 